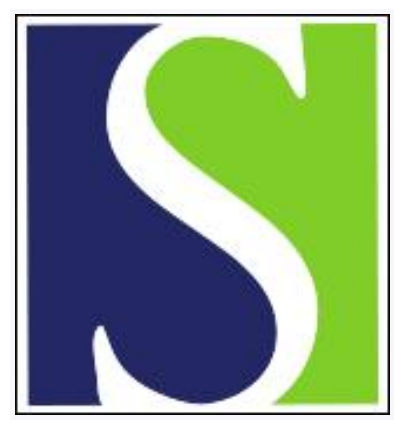

Scand J Work Environ Health 2007;33(4):245-251

https://doi.org/10.5271/sjweh.1139

Issue date: 31 Aug 2007

\title{
Citation classics in occupational medicine journals
}

by Gehanno JF, Takahashi K, Darmoni S, Weber J

Affiliation: Institute of Occupational Health, Rouen University Hospital, 1 rue de Germont, 76000 Rouen cedix, France. jean-francois.gehanno@chu-rouen.fr

The following articles refer to this text: 2007;33(4):241-243;

2007;33(5):397-399; 2009;35(6):461-465; SJWEH Supplements 2009;(7):41-47; 2010;36(6):515-516; 2015;41(5):421-424;

2020;46(1):1-4

Key terms: bibliometrics; citation classic; numerical data; occupational health; occupational medicine journal; periodical; statistics

This article in PubMed: www.ncbi.nlm.nih.gov/pubmed/17717615 


\title{
Citation classics in occupational medicine journals
}

\author{
by Jean-François Gehanno, MD, ${ }^{1}$ Ken Takahashi, MD, ${ }^{2}$ Stephan Darmoni, MD, ${ }^{3}$ Jacques Weber, MD ${ }^{4}$
}

\begin{abstract}
Gehanno JF, Takahashi K, Darmoni S, Weber J. Citation classics in occupational medicine journals. Scand J Work Environ Health 2007;33(4):245-251
\end{abstract}

Objectives The number of citations an article receives after its publication not only reflects its impact on the
scientific community, but also the impact of the institutions or countries in the field studied. In 1987, Garfield
introduced the concept of "citation classics" for the best-cited articles. An analysis of top-cited articles coming
from journals in the field of occupational medicine (eg, Occupational and Environmental Medicine, Scandina-
vian Journal of Work, Environment \& Health) has not yet been reported. The purpose of this study was to assess
whether or not such citation classics exist in this field and to analyze their characteristics.
Methods The most frequently cited articles published in the five major journals in occupational medicine were
identified using the database of Science Citation Index Expanded. The data were obtained by searching one year
and one journal at a time. All of the articles cited more than 100 times were collected and analyzed.
Results Among the 15553 articles published by the five journals since 1949 , only 85 articles had been cited
more than 100 times. The oldest had been published in 1950 and the latest in 1997 . The United Kingdom con-
tributed $28 \%$ of the citation classics and the United States or Sweden produced $19 \%$. The most cited article had
been cited 979 times. The main topics of articles were metabolism, occupational neoplasms, and work-related
musculoskeletal disorders.
Conclusions Since the 1980 s, Scandinavia and the United States have taken the leadership in the publication
of citation classic papers. Nevertheless, according to the level of citations, the influence of literature published
in occupational medicine journals remains limited.

Key terms bibliometrics; numerical data; occupational health; periodical; statistics.

The number of citations an article receives after its publication reflects its impact on the scientific community, but also the impact of the authors, a specific institution, or even a country in the field studied. Although citation statistics have been frequently criticized, the analysis of citation rates can allow for the identification of advances in a specialty and may provide a historical perspective of its scientific progress. In 1987, Garfield listed the "top 100" best-cited articles ever published in JAMA (1) and named them "citation classics". Since then, there have been a few recent attempts to identify and analyze citation classics for various specialties [ie, dermatology (2), critical care medicine (3), physical medicine (4) and general surgery (5), as well as for specific journals (6-8)].

However, the analysis of top-cited articles originating from periodicals in the field of occupational medicine has not yet been reported. The purpose of our present study was therefore to assess whether or not citation classics exist in occupational medicine and to determine the characteristics [ie, ranking (number of citations), year of publication, publishing journal, type of article, institution of origin, country, state, and topic of the most frequently cited articles published in prominent occupational medicine journals].

\section{Material and methods}

The five major journals in occupational medicine, according to their impact factor (Journal Citation Report, 2004) and to a previous study (9), were analyzed (table 1). The most frequently cited articles in these

1 Institute of Occupational Medicine, Rouen University Hospital, Rouen, France.

2 University of Occupational and Environmental Health, Kitakyushu, Japan.

3 Computer and Networks Department, Rouen University Hospital, Rouen, France.

4 Pedagogical Board, Rouen University Hospital, Rouen, France.

Correspondence to: Dr J-F Gehanno, Institute of Occupational Health, Rouen University Hospital, 1 rue de Germont, 76000 Rouen cedix, France. [E-mail: jean-francois.gehanno@chu-rouen.fr] 
Table 1. Number of papers published and number of "citation classic" papers published during the same period in five occupational medicine journals.

\begin{tabular}{lccccc}
\hline Journal & $\begin{array}{c}\text { Publication } \\
\text { period }\end{array}$ & $\begin{array}{c}\text { Articles } \\
\text { published } \\
\text { during the } \\
\text { period }\end{array}$ & $\begin{array}{c}\text { Impact } \\
\text { factor } \\
(2004)\end{array}$ & $\begin{array}{c}\text { Papers } \\
\text { cited } \\
>100 \text { times } \\
(\mathrm{N})\end{array}$ & $\begin{array}{c}\text { Citation classics } \\
\text { among the } \\
\text { published } \\
\text { papers }(\%)\end{array}$ \\
\hline American Journal of Industrial Medicine & & 4275 & 1.542 & 9 & 0.21 \\
Occupational and Environmental Medicine & $1980-$ & 4789 & 1.916 & 43 & 0.90 \\
International Archives of Occupational and Environmental Health & $1976-$ & 2333 & 1.388 & 6 & 0.26 \\
Journal of Occupational and Environmental Medicine & $1971-$ & 1505 & 1.472 & 0 & 0 \\
Scandinavian Journal of Work, Environment \& Health & $1975-$ & 2651 & 1.816 & 27 & 1.02 \\
\hline Total & & 15553 & & 85 & 0.56 \\
\hline
\end{tabular}

Table 2. Twenty most-cited citation classics in occupational medicine journals.

\begin{tabular}{|c|c|c|}
\hline Article & Times cited & Rank \\
\hline $\begin{array}{l}\text { Wagner JC, Sleggs CA, Marchand P. Diffuse pleural mesothelioma and asbestos exposure in the North Western Cape } \\
\text { Province. Br J Ind Med. 1960;17:260-71. }\end{array}$ & 979 & 1 \\
\hline $\begin{array}{l}\text { Bongers PM, de Winter CR, Kompier MAJ, Hildebrandt VH. Psychosocial factors at work and musculoskeletal disease } \\
\text { [review]. Scand J Work Environ Health. 1993;19(5):297-312. }\end{array}$ & 374 & 2 \\
\hline Silverstein BA, Fine LJ, Armstrong TJ. Occupational factors and carpal tunnel syndrome. Am J Ind Med. 1987;11(3):343-58. & 315 & 3 \\
\hline Barry PS. A comparison of concentrations of lead in human tissues. Br J Ind Med. 1975;32(2):119-39. & 304 & 4 \\
\hline Barnes JM, Magee PN. Some toxic properties of dimethyInitrosamine. Br J Ind Med. 1954;11(3):167-74. & 291 & 5 \\
\hline Clark DG, McElligott TF, Hurst EW. The toxicity of paraquat. Br J Ind Med. 1966;23(2):126-32. & 256 & 6 \\
\hline $\begin{array}{l}\text { Hagberg M, Wegman DH. Prevalence rates and odds ratios of shoulder-neck diseases in different occupational groups. } \\
\text { Br J Ind Med. 1987;44(9):602-10. }\end{array}$ & 253 & 7 \\
\hline $\begin{array}{l}\text { Newhouse ML, Thompson H. Mesothelioma of pleura and peritoneum following exposure to asbestos in the London area. } \\
\text { Br J Ind Med. 1965;22(4):261-9. }\end{array}$ & 252 & 8 \\
\hline Silverstein BA, Fine LJ, Armstrong TJ. Hand wrist cumulative trauma disorders in industry. Br J Ind Med. 1986;43(11):779-84. & 249 & 9 \\
\hline Fullerton PM, Barnes JM. Peripheral neuropathy in rats produced by acrylamide. Br J Ind Med. 1966;23(3):210-21. & 238 & 10 \\
\hline $\begin{array}{l}\text { Sato A, Nakajima T. Partition coefficients of some aromatic hydrocarbons and ketones in water, blood and oil. Br J Ind Med. } \\
\text { 1979;36(3):231-4. }\end{array}$ & 238 & 11 \\
\hline $\begin{array}{l}\text { McDonald JC, Liddell FD, Gibbs GW, Eyssen GE, McDonald AD. Dust exposure and mortality in chrysotile mining, 1910-75. } \\
\text { Br J Ind Med. 1980;37(1):11-24. }\end{array}$ & 231 & 12 \\
\hline $\begin{array}{l}\text { Eriksson M, Hardell L, Berg NO, Moller T, Axelson 0. Soft-tissue sarcomas and exposure to chemical substances: a case- } \\
\text { referent study. Br J Ind Med. 1981;38(1):27-33. }\end{array}$ & 228 & 13 \\
\hline $\begin{array}{l}\text { Elofsson S-A, Gamberale F, Hindmarsh T, Iregren A, Isaksson A, Johnsson I, et al. Exposure to organic solvents: a cross- } \\
\text { sectional epidemiologic investigation on occupationally exposed care and industrial spray painters with special reference to the } \\
\text { nervous system. Scand J Work Environ Health. 1980;6(4):239-73. }\end{array}$ & 225 & 14 \\
\hline $\begin{array}{l}\text { Blair A, Malker H, Cantor KP, Burmeister L, Wiklund K. Cancer among farmers: a review. Scand J Work Environ Health. } \\
\text { 1985;11(6):397-407. }\end{array}$ & 219 & 15 \\
\hline $\begin{array}{l}\text { Buchet JP, Lauwerys R, Roels H. Comparison of the urinary excretion of arsenic metabolites after a single oral dose of sodium } \\
\text { arsenite, monomethylarsonate, or dimethylarsinate in man. Int Arch Occup Environ Health. 1981;48(1):71-9. }\end{array}$ & 207 & 16 \\
\hline Lippmann M, Yeates DB, Albert RE. Deposition, retention, and clearance of inhaled particles. Br J Ind Med. 1980;37(4):337-62. & 200 & 17 \\
\hline $\begin{array}{l}\text { Donham K, Haglind P, Peterson Y, Rylander R, Belin L. Environmental and health studies of farm workers in Swedish swine } \\
\text { confinement buildings. Br J Ind Med. 1989;46(1):31-7. }\end{array}$ & 191 & 18 \\
\hline $\begin{array}{l}\text { Walpole AL, Williams MH, Roberts DC. The carcinogenic action of 4-aminodiphenyl and 3:2'-dimethyl-4-amino-diphenyl. } \\
\text { Br J Ind Med. 1952;9(4):255-63. }\end{array}$ & 187 & 19 \\
\hline $\begin{array}{l}\text { Nicholson WJ, Perkel G, Selikoff IJ. Occupational exposure to asbestos: population at risk and projected mortality- } \\
\text { 1980-2030. Am J Ind Med. 1982;3(3):259-311. }\end{array}$ & 181 & 20 \\
\hline
\end{tabular}

journals were identified using the database of Science Citation Index Expanded (SCI Expanded, 1945 to present). SCI Expanded is a multidisciplinary database powered by the Institute for Scientific Information (ISI) and the ISI Web of Science with searchable author abstracts covering the journal literature of the sciences; it indexes more than 6000 major journals across 164 scientific disciplines. Since the Cited Reference Search option of the Web of Science returns a site-configured maximum number of results, which is limited to 500 , the data were obtained by searching one year and one journal at a time.

All of the articles cited more than 100 times were collected and analyzed.

The papers were not weighted by age in the analysis, and the raw numbers of citations were used.

Two strategies were applied to analyze the subjects of each of these articles. The first was to describe by one word (eg, "metabolism", "cancer" or "workrelated musculoskeletal disorders") the main subject 
covered by each article. The second strategy was to collect all of the key words used to index each article in MEDLINE. These words were analyzed using two tools. The first was a medico-scientific data mining web service developed by the Institute for Medical Statistics and Epidemiology of the Technical University of Munich and named Meva (MEDLINE Evaluator) (http://www.med-ai.com/meva/index.html). This MEDLINE postprocessor condenses the list of a MEDLINE retrieval outcome into a structured result showing a graphic representation of the counts and relations of the MEDLINE fields by using frequency distributions, contingency tables, and detailed sorted lists. The second tool was a MEDLINE categorization algorithm (MCA), based on semantic links existing between Medical Subject Headings (MeSH) terms and metaterms on one hand and between MeSH subheadings and metaterms on the other. These links are used to automatically infer a list of metaterms from any MeSH term or subheading indexing (10).

\section{Results}

Among the 15553 articles published by the journals studied since 1949, 85 articles $(0.55 \%)$ had been cited more than 100 times (table 1).

The number of citation classics among all of the published papers varied widely between the studied journals, ranging from $0 \%$ to $1.02 \%$. For this indicator, the British Journal of Industrial Medicine and Occupational and Environmental Medicine were considered a single journal since the former became the latter in 1994.

The oldest citation classic was published in 1950 (102 citations) and the latest in 1997 (122 citations). Although the most cited article had been cited 979 times, $68 \%$ of the citation classics had been cited between 100 to 150 times. The "top twenty" papers, with their number of citations, are presented in table 2 on page 246 .

The articles covered a wide range of diseases and chemicals. Among the $1371 \mathrm{MeSH}$ descriptors used to index these articles, the most frequently used in categories C (diseases) and D (drugs and chemicals) are displayed in table 3 , together with their corresponding $\mathrm{MeSH}$ tree number. A total of 190 and 112 descriptors were used for categories $\mathrm{C}$ and $\mathrm{D}$, respectively. The most common key word for diseases was neoplasms (particularly thoracic neoplasms or mesotheliomas), followed by nervous system diseases (mainly peripheral nervous system diseases), respiratory tract diseases, and musculoskeletal diseases. Among the chemicals, hydrocarbons, metals, and asbestos were the most frequently cited.

The methods used in the articles were studied using the MCA. It demonstrated that epidemiology was the most frequent qualifier used in the MEDLINE indexation of the papers, followed by toxicology, statistics, and physiology, in decreasing order.

Overall, 14 articles dealt with the metabolism of xenobiotics $(16.5 \%)$, and $3(3.5 \%)$ concerned the toxicologic properties of xenobiotics. Some trends existed concerning these topics. Whereas between 2 and 5 citation classics dealing with fundamental toxicology or metabolism studies were published during each decade, citation classics concerning solvents appeared only during the 1970s and 1980s, and those concerning work-related musculoskeletal disorders emerged in the 1980s (3 papers) and increased significantly in the 1990s (10 papers out of the 21 citation classics identified during this decade). Altogether, 13 articles (15.3\%) were review articles.

The 85 top-cited articles originated from 13 countries, the United Kingdom contributing 26 (31\%) articles, followed by Sweden and the United States (US) with 16 articles each (table 4).

Table 3. Most frequent key words used in MEDLINE to index the 85 citation classics from five occupational medicine journals.

\begin{tabular}{|c|c|c|}
\hline MeSH tree number & Medical subject headings & $\begin{array}{l}\text { Ocurrence } \\
\text { (N) }\end{array}$ \\
\hline C & Diseases & 190 \\
\hline $\mathrm{CO4}$ & Neoplasms & 37 \\
\hline C04.557.337 & - Leukemia & 3 \\
\hline C04.557.450.795 & - Sarcoma & 3 \\
\hline C04.557.470.035.510 & - Mesothelioma & 4 \\
\hline C04.588.894.797.520 & - Lung neoplasms & 8 \\
\hline C04.588.894.797.640 & - Pleural neoplasms & 2 \\
\hline C05 & Musculoskeletal diseases & 11 \\
\hline C08 & Respiratory tract diseases & 13 \\
\hline C08.381.483.600.125 & - Asbestosis & 4 \\
\hline $\mathrm{C} 10$ & Nervous system diseases & 14 \\
\hline C10.668.829 & $\begin{array}{l}\text { - Peripheral nervous system } \\
\text { diseases }\end{array}$ & 6 \\
\hline C17.800 & Skin diseases & 5 \\
\hline C20.543.480 & Hypersensitivity, immediate & 7 \\
\hline C21.613.589 & Lead poisoning & 4 \\
\hline C23.550.848 & Stress & 3 \\
\hline D & Chemicals and drugs & 112 \\
\hline D01.268.556.175 & Chromium & 1 \\
\hline D01.268.556.435 & Lead & 4 \\
\hline D01.268.556.484 & Manganese & 2 \\
\hline D01.268.912.035 & Arsenic & 3 \\
\hline D01.268.912.540 & Manganese & 1 \\
\hline D01.268.912.575 & Nickel & 1 \\
\hline D01.837.725.700.760.070 & Asbestos & 4 \\
\hline D02.455 & Hydrocarbons & 20 \\
\hline D02.455.426.559.222 & - Benzene & 2 \\
\hline D02.455.426.559.389 & - Benzene derivatives & 8 \\
\hline D02.455.526 & - Hydrocarbons, halogenated & 4 \\
\hline D04.615 & Polycyclic hydrocarbons, aromatic & 6 \\
\hline D27 & Chemical actions and uses & 26 \\
\hline D27.720.723.366 & - Herbicides & 3 \\
\hline D27.720.844 & - Solvents & 6 \\
\hline
\end{tabular}


Only 53\% of the articles originated from Englishspeaking countries (figure 1).

When the papers were scrutinized according to the affiliation of the corresponding authors, the Catholic University of Louvain and the University of Michigan were the most important providers of citation classics, with 4 citation classics each (figure 1). It is significant to note that 8 citation classics (nearly 10\%) originated from the private sector, although from 8 different teams.

Table 4. Countries of origin of the citation classics from five occupational medicine journals.

\begin{tabular}{|c|c|c|c|c|c|c|}
\hline \multirow[t]{2}{*}{ Country } & \multicolumn{6}{|c|}{ Decade during which papers were published } \\
\hline & $1950 \mathrm{~s}$ & $1960 \mathrm{~s}$ & 1970s & 1980s & 1990s & Total \\
\hline United Kingdom & 7 & 8 & 6 & 4 & 1 & 26 \\
\hline Sweden & & & 6 & 8 & 2 & 16 \\
\hline United States & & & 1 & 9 & 6 & 16 \\
\hline Netherlands & & & & 2 & 3 & 5 \\
\hline Belgium & & & & 3 & 1 & 4 \\
\hline Finland & & & 3 & & 1 & 4 \\
\hline Canada & & & & & 3 & 3 \\
\hline Denmark & & & & 2 & 1 & 3 \\
\hline Germany & & & & 1 & 1 & 2 \\
\hline Japan & & & 2 & & & 2 \\
\hline Norway & & & & & 2 & 2 \\
\hline Morocco & 1 & & & & & 1 \\
\hline South Africa & & 1 & & & & 1 \\
\hline Total & 8 & 9 & 18 & 29 & 21 & 85 \\
\hline
\end{tabular}

A total of 270 authors contributed to these citation classics, some of them more than once. Axelson and Jongeneelen were the only authors to have written 3 citation classics, as first author, and Axelson was the only person to have co-authored 5 citation classics.

\section{Discussion}

The term citation classics was first introduced by Eugene Garfield in 1987 in a study to identify the 100 most-cited JAMA articles (1). In that study, the least-cited article received 158 citations. Since then, some authors have studied the citation classics in various specialties or among papers published by specific journals $(2-8$, 11-15). Although the least cited article in Garfield's study received 158 citations (1), the threshold used for according the status of citation classic to a paper as been set at "100 times cited" in many studies dealing with various medical or surgical specialties $(2,3,5,14,15)$, and we therefore adopted the same threshold.

This bibliometric review of citation classics in occupational medicine journals illustrates how this scientific field has evolved during the past 50 years and the importance of this field in comparison with other specialties.

Such a bibliometric study has the potential to identify most of the true landmark papers published in the journals studied, but some of the most important contributions published in the 1950s or 1960s may have

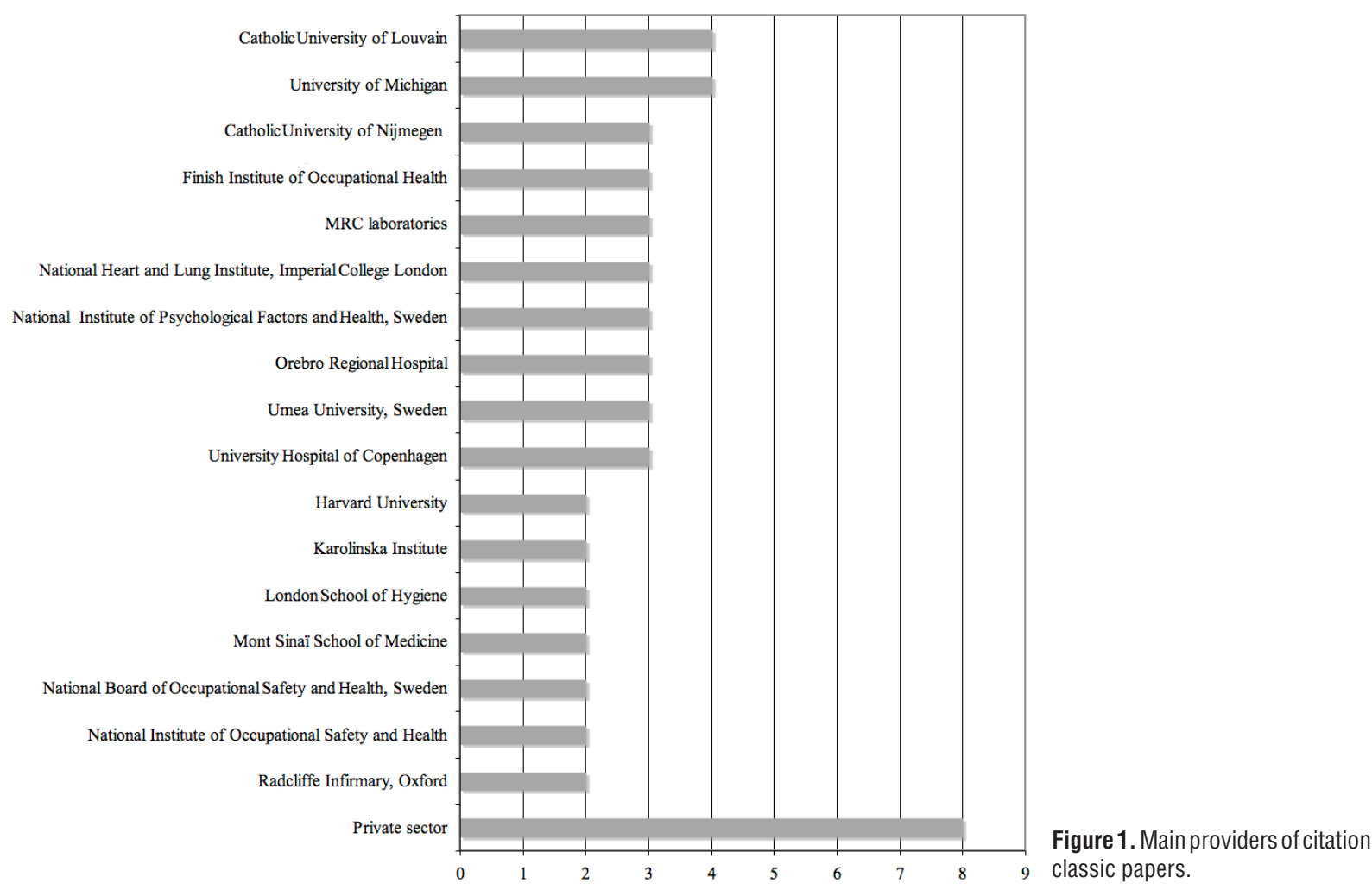


been overlooked. Yet, as time passes, even true classics are gradually being cited less often because their substance has been absorbed into current knowledge, a phenomenon called "obliteration by incorporation" (1). Thus the absolute number of citations an article has accumulated cannot be used as a sole measurement of its "importance." As Garfield (1) noted, the landmark article by Sabin et al, from 1960 (16), on the use of oral poliomyelitis virus vaccine received only 90 citations up to 1987. In fact, the true intellectual milestones may often be found in the reference lists of the top-cited papers (8).

It has been demonstrated that occupational medicine is a wide specialty that covers many different fields and that articles dealing with it are therefore published in a multitude of journals (9). Therefore, studying only the citation rate of papers published in occupational medicine journals is an underestimation of the number of citations classics in this field. In fact, in their study on the top-cited articles in critical care medicine, Baltussen \& Kindler (3) compared the citation rate of the articles originating from critical care journals with those concerning critical care but published in a noncritical care journal. The mean numbers of citations of the top 45 articles published in critical care journals and the top 45 articles published in noncritical care journals, mainly the most important general medical journals, were 440 and 810 , respectively (3). Nevertheless, the purpose of our research was to study the impact of occupational health journals, and not that of occupational health literature on the whole, which would have needed another methodology.

In our study, the number of articles cited more than 100 times was 85 , which is lower or comparable with the numbers of citation classics reported in the literature. For example, among the papers published in 65 general surgical journals between 1945 and 1995, 1500 had been cited more than 100 times, and 100 more than 278 times (5). The mean number of citations of the top 100 was 405 (range 278-1013). Absolute numbers of classic papers have also been reported for otolaryngology-head and neck surgery journals (80 papers between 1900 and 1999) (12), for clinical dermatological journals (129 papers between 1945 and 1990) (2), for critical care journals (418 papers between 1945 and 2003) (3), for the Journal of Trauma (80 papers between 1961 and 2004), or for the British Journal of Clinical Pharmacology (70 papers between 1974 and 2003) (11).

Although a rate for citation classics based on the total number of articles published in these studies would allow a more-reliable comparison between our results and studies previously published in the literature, this information is rarely available, except for three studies. The citation classic's rate of $0.55 \%$ in our study was lower than those reported for the British Journal of
Clinical Pharmacology $(1.1 \%, \mathrm{P}<0.001)(11)$, for critical care medicine journals $(0.84 \%, \mathrm{P}<0.001)(3)$, and for the Journal of Trauma $(0.63 \%, \mathrm{P}=0.39)$ (14).

Therefore, the number of citation classics in occupational medicine appears to be limited. This situation probably reflects the low level of influence of occupational medicine journals, as is also indicated by the low level of the impact factor of the five major periodicals in this field, always lower than or equal to 2 . While studying the influence of occupational medicine on general medicine, McCunney \& Harzbecker (17) showed that occupational medicine journals (hence articles) were nearly 50 times more likely to cite the general medical literature than the opposite.

All of our 85 citation classics were about etiologic studies or occupational exposure. None of them concerned occupational health intervention. Nevertheless, as recently pointed out by Ruotsalainen et al (18), there is a relative paucity of clinically relevant and methodologically well-conducted occupational health intervention studies in the occupational health literature. Despite the recent overall improvement in the number and quality of such studies, the fact that no such studies have had time to become a citation classic is therefore not surprising.

Browsing through the most-cited articles, we observed that, among the many true-landmark contributions, there are articles dealing with topics that were "hot", or popular, at one time and then ceased to be so. The topics covered by the citation classics originating from occupational medicine journals reveals the dominance of basic science [ie, of studies on the metabolism or toxicologic properties of industrial compounds and of traditional risks in occupational medicine (eg, cancers, effects of asbestos, solvents, or metals)]. The number of papers dealing with work-related musculoskeletal disorders was underestimated by the analysis of MeSH descriptors since these disorders include a group of conditions that involve the nerves, tendons, muscles, and supporting structures such as intervertebral discs and can thus be indexed under nervous system diseases or musculoskeletal disorders in MEDLINE. Overall, $13(15.3 \%)$ of the 85 citation classics had work-related musculoskeletal disorders as their main subject. Nevertheless, musculoskeletal disorders gained a growing importance in the 1990s, namely, 10 out of 21 citation classics published during this decade concerned this topic. The place of new risks such as psychological disorders or the effects of shift work remains low, but is emerging, as reflected by the second rank of the paper written by Bongers et al (table 2). As reported by Terajima \& Aneman (19), this change reflects the fact that these topics emerged recently and that it takes some time to achieve "classic" status, even in the era of the Internet. Furthermore, this latency is also influenced by the low (17) immediacy index (ie, the average number of 
times that an article published in a specific year within a specific journal is cited over the course of that same year) and the long cited half-life (ie, the number of years, going back from the current year, that account for $50 \%$ of the total citations received by the cited journal in the current year) of occupational and environmental health literature. Yet, in 2002, the cited half-life of $O c$ cupational and Environmental Medicine was 4.8 years, and the cited half-life of other periodicals in this field, such as the Journal of Occupational and Environmental Medicine or the Scandinavian Journal of Work Environment \& Health were, respectively, 8.2 and 8.4 years (Journal of Citation Reports. 2002:113-114).

Although it has been claimed that, with increasing age, each paper has more time to be cited (8), our analysis shows that $59 \%$ of the citation classics were published after 1980. The development of bibliographic databases, particularly PubMed, and their availability on the Internet since the 1990s is probably the main factor explaining this trend.

The papers originated from 13 different countries, with a very high proportion of non-English-speaking countries. Not surprisingly, during the years when the only international journal covering occupational medicine was the British Journal of Industrial Medicine, nearly all of the articles originated from the United Kingdom. Nevertheless, since the 1970s, the Scandinavian countries, and, notably, Sweden and to a less extent Finland, have published a growing number of citation classics, exceeding those originating from the United States. This trend is very different from the one observed by other studies made on citation classics in other specialties, which have usually identified the United States as the most contributing country $(1,3,5,19)$.

Considering that most occupational health research is published outside occupational health journals (9), our study clearly does not provide an exhaustive view of the trends in that field. Nevertheless, it gives an opportunity to assess the influence of periodicals in the field of occupational medicine, which appears to be limited.

Additional studies on the real impact of occupational medicine papers on the whole, including those published in nonoccupational medicine journals, would therefore be warranted.

In conclusion, to our knowledge, this study is the first reported attempt to identify citation classics in occupational medicine journals. These results confirm the low influence of occupational health journals on the whole, except for a very few number of papers that have brought new insights concerning epidemiologic evidence on the toxic effects of metals, asbestos, or solvents, which revealed the metabolism of common workplace pollutants or proposed a comprehensive approach to the occupational etiology of some occupational diseases, such as work-related musculoskeletal disorders.
Among the possible causes, we can mention that very few occupational medicine journals provide free access to their content via the Internet, except $\mathrm{Occu}$ pational and Environmental Medicine for papers older than 1 year.

It is difficult to know whether our observations can be generalized to the occupational health literature on the whole, and a study on citation classics for occupational medicine papers published in general medical journals would therefore be interesting.

The method used in this study provides useful insights concerning the institutes and countries who are leaders in terms of research and thereof publication in occupational medicine journals, and it displayed the influence of Scandinavian and Benelux countries.

Furthermore, identifying the most important papers in our field is not only of historical interest, but is also relevant in terms of education since these papers, which have influenced occupational medicine, should be included in the curriculum for occupational health students, among other landmark papers on occupational medicine published in prominent general medicine journals.

\section{Acknowledgments}

The authors thank Richard Medeiros, medical editor at the Rouen University Hospital, for his valuable advice in editing the manuscript.

\section{References}

1. Garfield E. 100 citation classics from the Journal of the American Medical Association. JAMA. 1987; 257:52-9.

2. Dubin D, Hafner AW, Arndt KA. Citation classics in clinical dermatologic journals: citation analysis, biomedical journals, and landmark articles, 1945-1990. Arch Dermatol. 1993;129:1121-9.

3. Baltussen A, Kindler $\mathrm{CH}$. Citation classics in critical care medicine. Intensive Care Med. 2004;30:902-10.

4. Key JD. Citation classics: most-cited articles from Archives of PM\&R. Arch Phys Med Rehabil. 1988;69:1058-9.

5. Paladugu R, Schein M, Gardezi S, Wise L. One hundred citation classics in general surgical journals. World J Surg. 2002;26:1099-105.

6. Albert DM. Analysis of the Archives' most frequently cited articles. Arch Ophthalmol. 1988;106:465-70.

7. Key JD, Kempers RD. Citation classics: most-cited articles from Fertility and Sterility. Fertil Steril. 1987;47:910-15.

8. Picknett T, Davis K. The 100 most-cited articles from JMB. J Mol Biol. 1999;293:171-6.

9. Gehanno JF, Thirion B. How to select publications on occupational health: the usefulness of Medline and the impact factor. Occup Environ Med. 2000;57:706-9. 
10. Darmoni SJ, Neveol A, Renard JM, Gehanno JF, Soualmia LF, Dahamna B, et al. A MEDLINE categorization algorithm. BMC Med Inform Decis Mak. 2006;6:7.

11. Aronson JK. Citation classics in the British Journal of Clinical Pharmacology, 1974-2003. Br J Clin Pharmacol. 2004;58: S699-S702.

12. Fenton JE, Roy D, Hughes JP, Jones AS. A century of citation classics in otolaryngology-head and neck Surgery journals. J Laryngol Otol. 2002;116:494-8.

13. Hall GM. BJA citation classics 1945-1992. Br J Anaesth. 1998;80:4-6.

14. Ollerton JE, Sugrue M. Citation classics in trauma. J Trauma. 2005;58:364-9.

15. Thomas K, Moore CM, Gerharz EW, O'Brien T, Emberton M. Classic papers in Urology. Eur Urol. 2003;43:591-5.

16. Sabin AB, Ramos-Alvarez M, Alvarez-Amezquita J, Pelon W,
Michaels RH, Spigland I, et al. Live, orally given poliovirus vaccine: effects of rapid mass immunization on population under conditions of massive enteric infection with other viruses. JAMA. 1960;173:1521-6.

17. McCunney RJ, Harzbecker J. The influence of occupational medicine on general medicine: a look at the journals. J Occup Med. 1992;34:279-86.

18. Ruotsalainen JH, Verbeek JH, Salmi JA, Jauhiainen M, Laamanen I, Pasternack I, et al. Evidence on the effectiveness of occupational health interventions. Am J Ind Med. 2006;49:865-72.

19. Terajima K, Aneman A. Citation classics in anaesthesia and pain journals: a literature review in the era of the internet. Acta Anaesthesiol Scand. 2003;47:655-63.

Received for publication: 1 December 2006 